\title{
A Revista Matéria e o 8을 Congresso Brasileiro de Carbono
}

Sandro Campos Amico ${ }^{1}$ e Honória de Fátima Gorgulho ${ }^{2}$

\author{
${ }^{1}$ Editor-associado \\ Universidade Federal do Rio Grande do Sul - UFRGS, Av. Bento Gonçalves, 9500, 91501-970, Porto \\ Alegre, RS, Brasil. e-mail: amico@ufrgs.br \\ ${ }^{2}$ Coordenadora do Carbono-2019 \\ Universidade Federal de São João del-Rei (UFSJ), Praça Dom Helvécio, 74, 36301-160, São João del- \\ Rei, MG, Brasil. e-mail: gorgulho@ufsj.edu.br
}

A Revista Matéria participa ativamente da divulgação da pesquisa desenvolvida no Brasil e se associou ao longo dos seus anos de atuação [1] a congressos científicos para a publicação de artigos selecionados. A publicação em revista de versões estendidas de trabalhos de congressos após revisão pelos pares, aprofundando a discussão do conteúdo, dá visibilidade aos pesquisadores envolvidos em um cenário cada vez mais competitivo.

Nesta edição da Revista Matéria, além de artigos submetidos regularmente nas diferentes áreas do seu escopo, estão incluídos artigos derivados de trabalhos apresentados no $8^{\circ}$ Congresso Brasileiro de Carbono, o CARBONO 2019. Este congresso se destaca como o principal evento nacional para os profissionais envolvidos com a pesquisa e produção de diferentes materiais de carbono. O congresso representa uma grande oportunidade de divulgar e compartilhar conhecimentos técnicos e científicos nesta área, incentivando inovações tecnológicas. A oitava edição do CARBONO ocorreu, pela primeira vez, no estado de Minas Gerais, na histórica cidade de São João del-Rei. O evento foi promovido por docentes do Departamento de Ciências Naturais (DCNat) da Universidade Federal de São João del-Rei (UFSJ)), em conjunto com o Instituto Federal do Sudeste de Minas Gerais (IFSMG), o Centro de Desenvolvimento da Tecnologia Nuclear (CDTN-MG) e a Associação Brasileira de Carbono (ABCarb), com a participação de alunos de iniciação científica e de pós-graduação.

Os artigos escolhidos para esse número da Revista Matéria refletem a grande diversidade de aplicações deste material como, por exemplo, na produção de capacitores, adsorventes, catalisadores, compósitos, eletrônicos e materiais biomédicos. Tais materiais diferem na estrutura, nas propriedades e no método de fabricação, e por isso, são objeto de intensa pesquisa em áreas estratégicas, abrangendo temas com forte relevância para a ciência e a tecnologia.

Desejamos a todos uma boa leitura!

BIBLIOGRAFIA

[1] MONTEIRO, S.N., “A Revista Matéria associa-se ao Congresso Anual da ABM”, Matéria (Rio de Janeiro), v. 11, n. 3, pp. 173-173, 2006.

ORCID

Sandro Campos Amico

Honória de Fátima Gorgulho https://orcid.org/0000-0003-4873-2238

https://orcid.org/0000-0002-9557-6808 